\title{
Research on the Present Situation Evaluation and Promotion Countermeasure of Citizens' Scientific Literacy in Jiangxi Province
}

\author{
$\mathrm{Ju}-\mathrm{xin} \mathrm{Wu}$ \\ Graduate School \\ Jiangxi University of Traditional Chinese Medicine \\ Nanchang, Jiangxi, China \\ Tina-lin Chen \\ Psychological Counseling Center \\ Jiangxi University of Traditional Chinese Medicine \\ Nanchang, Jiangxi, China
}

\author{
Lan Luo \\ School of Humanities \\ Jiangxi University of Traditional Chinese Medicine \\ Nanchang, Jiangxi, China \\ Guang Chen \\ School of Economy and Management \\ Jiangxi University of Traditional Chinese Medicine \\ Nanchang, Jiangxi, China
}

\begin{abstract}
The citizens' scientific literacy, as the premise of people's self-development, also the source of national innovation and development, constitutes an important part of a country's comprehensive national strength. And for the in-depth understanding of the scientific literacy of citizens, the insight into the status quo of scientific literacy is required. This paper analyzes the overall scientific literacy level for Jiangxi citizens, as well as the existing problems and reasons for this situation in detail. The author hopes to provide references for the citizens scientific literacy construction, and make a contribution to improving the level of scientific literacy of Jiangxi citizens. Through careful analysis of the present situation of Jiangxi citizens' scientific literacy and the grasp of the situation of popular science work in the city, it is conducive to further implement the outline of civic scientific literacy action plan (2006-2010-2006) ". In addition, the author puts forward some corresponding suggestions in accordance with the characteristics and problems existing in the citizens' scientific literacy in the city
\end{abstract}

Keywords-Citizen's Scientific quality; Present situation Evaluation; Jiangxi province; Problems and reasons; Countermeasures

\section{INTRODUCTION}

International popular science theorists believe that "mastering scientific methods is the most important content in scientific quality".

In 2006, the State Council promulgated the outline of the National Action Plan on Scientific Literacy (2006-2010-2020), and put forward that by 2020, scientific and technological education, dissemination and popularization will have much more progress, form a more perfect citizen science quality of the construction of the organization, infrastructure, conditions such as security, monitoring and evaluation system, and citizens in a dramatic increase in overall, scientific quality reached the level of the world's major developed countries at the beginning of the 21 st century. Since the implementation of the Outline, especially during the "Twelfth Five-Year Plan" period, various localities and departments have focused on the overall development of the Party and the country, and have collaborated with each other. The scientific literacy of minors, farmers, urban workers, leading cadres, civil servants and community residents has been steadily promoted, which has led to the overall improvement of the scientific quality of the whole people. The work of science and technology education, communication and popularization has been extensively and deeply carried out. The resources for science popularization have been continuously enriched. In order to disseminate science and technology enhanced the ability of the mass media, especially the new media, the construction of infrastructure has continued to advance, Infrastructure construction continues to advance and the number of talented people continues to grow. The ability of public service in the construction of citizens' scientific quality has been further enhanced. The construction mechanism of citizen's scientific quality is basically established, and the situation of great union and great cooperation is further formed, which provides the guarantee for the smooth development of the scientific quality work of the whole people. 


\section{THE PRESENT SITUATION OF CITIZEN'S SCIENTIFIC QUALITY}

According to the Ninth Survey on the Scientific quality of Chinese Citizens, In 2015, the proportion of Chinese citizens with scientific quality reached $6.20 \%$, up nearly $90 \%$ from $3.27 \%$ in 2010. In order to lay a solid foundation for the scientific quality work of the whole people in the 13th Five-Year Plan, the level of scientific quality of citizens in China has reached the goal of $5 \%$ over the 12 th Five-Year Plan.

However, we should also see soberly that there is still a big gap about the level of scientific quality between china and developed countries. In 1989, the scientific quality of the Canadian public reached $4 \%$ of the basic scientific quality level. In 1991, the Japanese public had a scientific literacy rate of 3 percent. In 1992, the European Community reached 5\% of the basic scientific literacy level. In 2000, the proportion of American public scientific quality reached the basic scientific quality level, it is almost reached $17 \%$.In comparison with Japan, the United States and 15 European Union countries in 2001, our country ranks at the bottom in terms of understanding of scientific methods. Sweden ranks first in terms of knowledge of science, and China is almost the last [1].

The development of scientific quality of the whole people is still unbalanced, which cannot meet the needs of building a moderately prosperous society in all respects and building an innovative country. It is mainly manifested in the fact that the scientific quality of the whole population is still weak for the farmers, the new residents of the town, the remote areas and the people in the minority areas, and the education of the youth science and technology needs to be strengthened. The technical means of science popularization are relatively backward, equalization and precision service ability need to be improved urgently; the input of science popularization is insufficient, the incentive mechanism of the whole society participation is not perfect, and the function of market allocation resources is not played enough.

In March 2016, the General Office of the State Council issued the "Plan of Action for the implementation of the Action Plan for the Scientific quality of the whole people (20162020)", which made an overall plan for the realization of leapfrogging and upgrading of the scientific quality of Chinese citizens during the 13th Five-Year Plan period.

The quality of citizen science is the basis of implementing innovation-driven development strategy, it is the performance of national comprehensive national strength. Therefore, it is necessary to improve the scientific quality of the whole people, stimulate the enthusiasm and potential of mass innovation and entrepreneurship, lay a solid foundation for innovation-driven development and the great victory in the decisive stage of building a well-off society in an all-round way [2].

\section{PROBLEMS AND REASONS}

\section{A. The scientific quality of the whole people is low}

There is a big problem in the recognition of the scientific quality of the whole people. From kindergarten onwards, the educational evaluation index in students' minds is "good or bad grades", if they get excellent results at school, they will be loved by their parents ,praised by their teachers and envied by the students; If they fail the exam, they will be scolded by parents, criticized by teachers and ridiculed by their classmates. From very young age until now, psychology always keeps this unfair evaluation: mechanism-achievement is the foundation of everything. Other evaluation indicators are like an invisible hand, which is optional, but it is not a fatal requirement, as long as the results are good, everything can be negotiated. [3]Although the inner heart is unwilling to accept this kind of evaluation mechanism, but they can do nothing because its own scientific quality recognition is low and powerless, that has led to this pattern.

\section{B. Lack of scientific quality construction platform}

Today's society is a "face-looking" society. Nowadays, most people only pay attention to appearance, but do not care about internal construction, which often brings many disadvantages. They thought the interior would be advanced when they looked bright, but the fact is just the opposite. At present, many colleges and universities have gone astray, they think that scientific literacy construction platform is just a teaching building and the construction of school "face project", which ignores the improvement of experiment, practice equipment and the teaching condition of "internal project". Each university campus has excellent teaching environment, campus environment and advanced experimental equipment in line with the society, so as to provide students with exploration, innovation and simulation of the experimental conditions of the workplace [4]. Nowadays, people have a lack of practical ability, because the leaders of colleges and universities have a low understanding of practice. They have serious problems in introducing and training teachers. They pay more attention to the teachers in the lectures, thus neglecting the experimental teachers, which leads to the lack of scientific quality.

\section{Backward way of education}

Our education has always been in the state of examinationoriented education, which makes it more difficult to improve the scientific quality of the whole people. Primary and secondary education is the foundation of university education. The scientific quality of people is seriously affected by the problems of primary and secondary education. The learning goal of students and teachers in the primary and secondary school is to get a higher degree, so that they can win honor for both parents and teachers and get rid of the difficult life. However, they did not see the disadvantages of this type of education. Division of Arts and Sciences in Senior Grade One will bring the defect of knowledge structure to the students. Learning the humanities makes you know more about people; learning the social sciences makes you understand society better; learning the natural sciences makes you understand nature better. Living in the present society, you only understand one side, that is far from enough. Therefore, in 
addition to learning one of the sciences, we also need to learn other sciences in order to achieve the goal of integrating humanities and science. This kind of examination-oriented education method leads to the students' learning purpose is not clear, their learning attitude is not positive, their learning method is not correct, and the "rigid" teaching mode makes the students lose their enthusiasm, autonomy and initiative in learning.

\section{COUNTERMEASURES TO IMPROVE THE SCIENTIFIC QUALITY OF THE WHOLE PEOPLE}

\section{A. Change the concept of scientific quality consciousness}

The consciousness of scientific quality has a strong guiding function on scientific behavior and scientific judgment ability. In order to improve the scientific quality, it is necessary to change the concept of scientific quality consciousness. It is necessary to realize that good scientific quality is conducive to improve the comprehensive quality of human beings, and should consciously strengthen learning and improvement in the light of individual weakness. Students should make rational use of school resources and consciously integrate the transformation and improvement of scientific quality consciousness into their daily life and study. They should not only learn scientific knowledge in class, but also attach importance to the study of experiment and practice. Cultivate the scientific spirit of hard work and perseverance. Parents should also change their awareness of scientific quality. In their minds, achievement is the standard of talent evaluation, reading is the only way to stand out in a person's life, it leads parents ignore to cultivate the ability of their children, moral training, interest [4]. Therefore, parents should not blindly pursue children to achieve excellent results, but also pay attention to the scientific quality of children.

\section{B. Improve the construction of teaching staff.}

In order to improve the scientific quality of citizens, we need a team with high quality, strong ability and a large number of teachers. To improve the construction of teaching staff, we need to actively guide the integration of culture, technology and education into teaching. Excellent teachers are the source power to improve scientific quality. If there is no high-quality teachers, we can not cultivate talents with scientific quality .Improving the construction of teachers is the key to promote the cultivation of scientific quality. Teachers mainly improve their teaching ability and comprehensive quality. The teacher's teaching ability is mainly manifested in the following aspects: having advanced educational ideas, paying attention to the all-round development of students, having solid professional knowledge and skills, having the ability of educational research and the concept of lifelong learning. The comprehensive quality of the teacher is mainly reflected in the spirit of innovation and exploration, the lofty moral character and the spirit of serious responsibility to the students, the good sense of social responsibility and the noble professional ethics. Therefore, we should strengthen the management of teachers, establish a sound inspection, evaluation and supervision of the teaching mechanism. Teachers should be constantly arranged to learn advanced teaching methods and techniques so that they can understand the trend of the development of modern education better, which can better improve the scientific quality of citizens.

\section{Speed up the construction of infrastructure}

In the rapid development of science and technology today, without the high level of experimental facilities, the scientific quality of the whole people is lack of basic support. Many colleges and universities have the problem of incomplete facilities, so we should make full use of the existing infrastructure resources. We must have plans to open research and development centers and laboratories in primary and secondary schools. The government should also strengthen the management and control of the teaching infrastructure, according to the requirements of the school it can construct experimental facilities reasonably and efficiently. These scientific establishments should be open to the public, improve the utilization of infrastructure resources, [5] and improve the scientific quality of the whole people.

\section{Increase investment in scientific quality}

In 2006, China began to implement the outline of the Action Plan for the quality of Science of the whole people. It is planned that, in 2049 all citizens above the age of 18 can achieve the expected level of scientific quality. The government should adopt supporting and encouraging policies, such as encouraging and supporting the society to raise funds to invest in the construction of scientific quality, and supporting individuals to invest in the construction of scientific quality, so that scientific quality can be established as a cultural industry. Let citizens all over the country participate in the construction of scientific quality. At present, the Chinese government vigorously support individual researchers, research on the construction of venues and infrastructure platform, it provides favorable conditions for the majority of scientific and technical personnel and the basic knowledge of science communication. Nowadays, the coverage of scientific quality in media is not broad enough, and there are few websites that can obtain relevant scientific quality from the Internet. Therefore, media publicity should be strengthened. There should also be more TV programs about scientific quality and natural science. More and more people can learn scientific knowledge from TV, thus improving the scientific quality of the whole people.

\section{CONCLUSION}

This thesis has researched the present situation Evaluation and Promotion Countermeasure of Citizen's Scientific quality in Jiangxi Province. International popular science theorists believe that "mastering scientific methods is the most important content in scientific quality". The citizen's scientific quality is the foundation of implementing the strategy of innovation-driven development and the expression of the national comprehensive national strength. Therefore, we must constantly improve the scientific quality of the whole people. This paper summarizes the development course of the scientific quality of citizens in China, and compares our country with developed countries. We should soberly see that there is still a big gap between China and developed countries in the level of scientific quality of citizens at present, and our country is still in line with Japan in 2001.The United States, the European Union, 15 countries compared to the level of 
understanding of scientific methods, our country ranks at the bottom. China is also at the bottom of the list in terms of understanding of scientific knowledge.

\section{REFERENCES}

[1] Baidu library. A brief analysis on the current situation and countermeasures of Chinese citizens' scientific quality. [EB/OL] http: / /wenku.baidu.com/link? url= fsd6ueGthwWriJuhdi02K R UFiWNyXuxyNUCk3wOCHipZeEI2ZHUF3Jzp6xm5NJPZz2iMcz47m EumSQB8X1 2cU8e - foIQ4WfubSZIPGrUhe, 2013 - 03 - 23. (In Chinese)

[2] Baidu encyclopedia. Scientific quality. [EB/OL] http: / /baike. Baidu. com/link? url = e3kipo56 qGP95hjCUdCzcW8OxbU7fZO0M3g1Jjq5jfx32dGLU - Q3FJW CaO RQfyyN- QDo - KvCt0sM81adi1.2016 - 03 - 15. (In Chinese)

[3] Xian-ping SHAO. On the problems and Countermeasures of Scientific Quality-oriented Education for College students [J]. Educational research, 2011(2):1 - 4. (In Chinese)

[4] Hong LIANG. The role of Scientific quality in the Construction of an innovative country $[\mathrm{J}]$. Journal of education college in hubei province. 2015(1):53 - 54.(In Chinese)

[5] Chang-chun BO. International comparison of policies and regulations on popular Science and suggestions for improving Citizen's Scientific quality [J]. $1-8$. (In Chinese) 